\title{
Coopetition in Intermodal Freight Transport Services
}

\author{
Jian Liu, ${ }^{1}$ Yinzhen $\mathrm{Li}^{1}{ }^{1}$ and ${\mathrm{Jun} \mathrm{Li}^{2}}^{2}$ \\ ${ }^{1}$ School of Traffic and Transportation, Lanzhou Jiaotong University, Lanzhou 730070, China \\ ${ }^{2}$ School of Economics and Management, Southwest Jiaotong University, Chengdu 610031, China \\ Correspondence should be addressed to Jian Liu; liujianlz@sohu.com
}

Received 24 October 2014; Accepted 27 January 2015

Academic Editor: Driss Boutat

Copyright (C) 2015 Jian Liu et al. This is an open access article distributed under the Creative Commons Attribution License, which permits unrestricted use, distribution, and reproduction in any medium, provided the original work is properly cited.

\begin{abstract}
The paper studies the coopetition of the downstream different carriers by providing complementary transport services in intermodal freight transport chain. Considering different information structure, a two-stage dynamic game model with simultaneous actions on investment and price is first formulated. Equilibria show both parties have motivation to select coopetition even if the agreement for cooperation investment is reached in advance. When both firms agree on the specific allocation, the new coopetition with higher efficiency would be emerged. Moreover, we analyze the complexity and evolution of coopetition by repeated pricing game with finitely and infinitely time horizon. In the finitely repeated pricing game, both firms have incentive to reach a tacit understanding to alternate choosing price cooperation and competition after setting suitable allocation scheme; the repeated periods $t$ are then going to be an issue. In the infinitely repeated pricing game, the perfect cooperation is realized by designing the suitable trigger strategy.
\end{abstract}

\section{Introduction}

With the development of modern networked economy, the traditional competition concept of business is giving way to the new idea of coopetition. Coopetition is a new kind of perspective that both competition and cooperation coexist together. Competing elements always breed conflicts when either of the party's needs are not compatible for the existence of opportunistic and exploitative behavior. Cooperative elements can nourish joint payoff creation through exploiting complementary resources cooperatively. Therefore, in order to get better development in the marketplace, more cooperative elements are taken into consideration by firms to maximize inter-firms profits.

These developments have motivated the academic community to explore the coopetition strategy for interfirms. Coopetition is mentioned in the literature for the first time in 1913 [1]. In 1996 Brandburger and Nalebuff [2] gave a comprehensive theoretical research on coopetition; they argued that the competing and collaborating elements were entailed simultaneously to the interdependence in course of maximizing their individual profits. The complementarity to separate firms is an outstanding feature to induce the coopetition.
The role of cooperation with respect to equilibria has been extensively addressed in the literature for a long time. Most current studies focus on how to realize coordination under the competitive setting in product supply chain but are rarely related to transport industry especially to intermodal operations. In a decentralized supply chain, the supplier coordinates the downstream behaviors by designing inventive mechanism such that all numbers align their objectives with system objective. A variety of effective contract coordination mechanisms have been studied to improve the decentralized system efficiency in supply chain (e.g., [3-6]). Gurnani et al. [7] studied the impact of product pricing and timing of investment decisions on supply chain coopetition; the result shows the incentives of the coopetition partners and the investment levels are mainly governed by the cost structure and the level of uncertainty in demand. In fact, the situation where two firms both compete and cooperate is frequently found in the transport industry. An example is in intermodal freight market, segment carriers that compete on tariffs and complement each other by feeding freights for further transport to the other provider.

Intermodal is a kind of modern transportation organization method with which container combined many other 
transportation means [8]. In order to provide an integration and effective seamless door-to-door service, more than two separate firms providing sequential or simultaneous services are involved to form a logistics intermodal services chain. Clark et al. [9] argued that complementarity between transport modes can take place in different geographical markets, different transport markets, and different levels of service. These criteria can clearly be transferred to intermodal transport. Zhang et al. [10] examined the effect of multimodal integration on the rivalry between a forwarder-airline alliance and an integrator; they found an improvement in multimodal integration by a forwarder airline alliance, and it would not increase the alliance's output but improve both consumer surplus and total surplus. Liu et al. [11] studied the coordination between the separate carriers providing complementary services in intermodal freight market. By setting suitable penalty schemes the user equilibrium and system optimum can be simultaneously satisfied in an incomplete market.

In this paper, we focus on the nature of coopetition between two segment carriers in an intermodal logistics services chain. We consider two firms offering complementary and integrative transportation services in their respective local market. Two predominant factors of influencing intermodal transport demand are considered, namely, investment and price. For instance, in the transport industry, the investment on new type vehicle and collaborative networks would be beneficial to improve leading time and delivery rate; the demand was then stimulated to grow fast [12]. Due to the spillover effect, investment in technology or infrastructure by either firm would not only improve their transport service quality, but also benefit both logistics chain's partners by developing the potential intermodal market. Generally, the investment in infrastructure is a foundation work and often need to be committed before final demand information is revealed. Therefore, in our setting, such investments are considered before demand uncertainty is resolved. Moreover, the price decisions are subsequently made by separate firms independently to maximize their profits.

We first analyze a basic two-stage perfect game modal with simultaneous actions to explore coopetition behaviors. Equilibria are calculated and show that coopetition exists widely and is beneficial to both parties. We further discuss the nature of coopetition by finitely and infinitely repeated price game, and managerial insights are proposed subsequently.

The rest of the paper is organized as follows. Section 2 describes business background and sets up our basic model. The conditions of equilibria under different forms of coopetition are deduced subsequently. Section 3 provides the analysis with focus on the complexity and evolution of coopetition and the way to realize perfect cooperation. In Section 4 , a case study is used to testify the propositions. In the end, some concluding remarks are presented in Section 5.

\section{The Model}

2.1. Scenario and Notation. We consider a simple intermodal network, as depicted in Figure 1; the network consists of

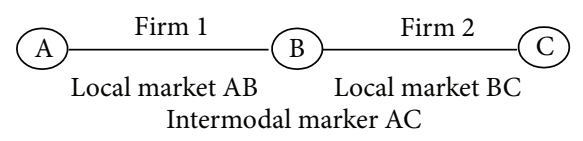

FIGURE 1: An intermodal market network.

three nodes, namely, A, B, and C. Consequently, there are three origin-destination markets, namely, $\mathrm{AB}, \mathrm{BC}$, and $\mathrm{AC}$. there are two separate local carriers, denoted by firm 1 and firm 2. The two firms both control transport infrastructure and provide freight transportation services in $\mathrm{AB}$ and $\mathrm{BC}$ transport market separately. Whilst AC involves two firms cooperation and may be referred to as a potential intermodal market. After market research, the two firms wish to make cooperation to develop long haul intermodal freight services. In order to ensure success the investment on development of infrastructure should be made first, and, then, the complicated price decisions to their segment market are dominated the debate subsequently.

The following notations are defined in this paper. For the AC market, the demand function $q$ may be written as

$$
q=D-p_{1}-p_{2}+\theta_{1} I_{1}+\theta_{2} I_{2}+\varepsilon
$$

where $D$ denotes the market size of AC market; $p_{i}$ is the transport price to local market by firm $i, i=1,2 ; p_{1}+$ $p_{2}$ is the final payment by shipper; $I_{i}$ is the investment on infrastructure to develop intermodal services by firm $i, i=$ 1,$2 ; \theta_{i}$ measures the influence of investment by firm $i$ to demand $i=1,2 ; \varepsilon$ is the error term on demand with mean 0 and standard deviation $\sigma$.

The firm $i$ 's profit function is $R_{i}=\left(p_{i}-c_{i}\right) q-1 / 2 \beta_{i} I_{i}^{2}+\varepsilon$, where $c_{i}$ is variable cost for firm $i, i=1,2$. A convex total investment cost is defined to be $1 / 2 \beta_{i} I_{i}^{2}$, where $\beta_{i}$ measures the influence to total investment cost, $i=1,2$.

In this paper, we will first consider a basic two-stage dynamic game model with simultaneous actions on investment and pricing sequential decision, and then an extended analysis is produced to disclose the nature of coopetition. Similar demand model has been used in the marketing literatures (e.g., [13-15]). Different from earlier studies, taking price and investment the focus of this paper will be directed towards firms with providing complementary services.

The timing of events is as follows: in stage one, two firms decide investment simultaneously. The improvement of infrastructure is necessary conditions for providing intermodal services; therefore two firms objective is to maximize their joint profit in this stage. Based on the results of stage one, two firms select price strategies by maximizing their individual profit in stage two.

We consider different information structures for two stages. Generally, investment on improvement of infrastructure often needs to be committed before final demand information for the intermodal services are revealed. Therefore, uncertainty in transport demand exists in stage one. On the other hand, price decisions can be postponed until after final demand potential is observed. 
The following assumptions are adopted in this paper.

(1) The two firms are all rational, and all parameters in model are common knowledge to both firms.

(2) In order to guarantee the nonnegativity of profit functions, the inequalities $9 \beta_{1}-8 \theta_{1}^{2}>0,9 \beta_{2}-8 \theta_{2}^{2}>0$ are satisfied. The two inequalities imply the unit of investment is more sensitive to the total cost than to the demand.

(3) The initial investment is necessary to forming intermodal services chain, so the two firms have a strong motivation to cooperate and high willingness to cooperate in stage one.

2.2. Basic Model. We first consider four basic strategies, that is, $\{$ cooperate + (cooperate, cooperate) $\}$; $\{$ cooperate + (compete, compete) $\}$; $\{$ cooperate + (cooperate, compete) $\}$; $\{$ cooperate + (compete, cooperate $)$. Each strategy is composed of two parts, that is, connected by " + ." The first part before "+" represents investment decision in stage one; the second part after "+” sequential represents two firm's price decision.

Strategy 1: $\{$ cooperate + (compete, compete $)\}$ In this strategy, the two firms cooperate on investment and then compete on price. Using backward induction algorithm to analyze the dynamic game, in stage two, after realization of investment, the separate firm's objective is

$$
\begin{aligned}
& \max _{p_{1}} R_{1}=\left(p_{1}-c_{1}\right)\left(D-p_{1}-p_{2}+\theta_{1} I_{1}+\theta_{2} I_{2}+\varepsilon\right)-\frac{1}{2 \beta_{1} I_{1}^{2}}, \\
& \max _{p_{2}} R_{2}=\left(p_{2}-c_{2}\right)\left(D-p_{1}-p_{2}+\theta_{1} I_{1}+\theta_{2} I_{2}+\varepsilon\right)-\frac{1}{2 \beta_{2} I_{2}^{2}} .
\end{aligned}
$$

From first order condition, the reaction functions are as follows:

$$
\begin{aligned}
& p_{1}\left(p_{2}\right)=\frac{D+c_{1}-p_{2}+I_{1} \theta_{1}+I_{2} \theta_{2}+\varepsilon}{2} \\
& p_{2}\left(p_{1}\right)=\frac{D-c_{2}-p_{1}+I_{1} \theta_{1}+I_{2} \theta_{2}+\varepsilon}{2} .
\end{aligned}
$$

We have

$$
\begin{aligned}
& p_{1}=\frac{2 c_{1}-c_{2}+D+I_{1} \theta_{1}+I_{2} \theta_{2}+\varepsilon}{3}, \\
& p_{2}=\frac{2 c_{2}-c_{1}+D+I_{1} \theta_{1}+I_{2} \theta_{2}+\varepsilon}{3} .
\end{aligned}
$$

In stage one, the objective function is to maximize the expected joint profit of the two firms:

$$
\begin{aligned}
\max _{I_{1}} E\left[R_{1}+R_{2}=\right. & \left(p_{1}+p_{2}-c_{2}-c_{1}\right) \\
& \cdot\left(D-p_{1}-p_{2}+\theta_{1} I_{1}+\theta_{2} I_{2}+\varepsilon\right) \\
& \left.-\frac{1}{2 \beta_{1} I_{1}^{2}}-\frac{1}{2 \beta_{2} I_{2}^{2}}\right],
\end{aligned}
$$

$$
\begin{aligned}
\max _{I_{2}} E\left[R_{1}+R_{2}=\right. & \left(p_{1}+p_{2}-c_{2}-c_{1}\right) \\
& \cdot\left(D-p_{1}-p_{2}+\theta_{1} I_{1}+\theta_{2} I_{2}+\varepsilon\right) \\
& \left.-\frac{1}{2 \beta_{1} I_{1}^{2}}-\frac{1}{2 \beta_{2} I_{2}^{2}}\right] .
\end{aligned}
$$

Substituting from (4) into (5) and the joint profit is concave as second condition is satisfied from assumption (2). Upon simplifying terms, we get

$$
\begin{aligned}
& I_{1}=\frac{4\left(D-c_{1}-c_{2}\right) \beta_{2} \theta_{1}}{9 \beta_{1} \beta_{2}-4 \beta_{2} \theta_{1}^{2}-4 \beta_{1} \theta_{2}^{2}}, \\
& I_{2}=\frac{4\left(D-c_{1}-c_{2}\right) \beta_{1} \theta_{2}}{9 \beta_{1} \beta_{2}-4 \beta_{2} \theta_{1}^{2}-4 \beta_{1} \theta_{2}^{2}}, \\
& p_{1}=c_{1}+\frac{\varepsilon}{3}+\frac{3\left(D-c_{1}-c_{2}\right) \beta_{1} \beta_{2}}{9 \beta_{1} \beta_{2}-4 \beta_{2} \theta_{1}^{2}-4 \beta_{1} \theta_{2}^{2}}, \\
& p_{2}=c_{2}+\frac{\varepsilon}{3}+\frac{3\left(D-c_{1}-c_{2}\right) \beta_{1} \beta_{2}}{9 \beta_{1} \beta_{2}-4 \beta_{2} \theta_{1}^{2}-4 \beta_{1} \theta_{2}^{2}}, \\
& R_{1}=\frac{\left(D-c_{1}-c_{2}\right)^{2} \beta_{1} \beta_{2}^{2}\left(9 \beta_{1}-8 \theta_{1}^{2}\right)}{\left(9 \beta_{1} \beta_{2}-4 \beta_{2} \theta_{1}^{2}-4 \beta_{1} \theta_{2}^{2}\right)^{2}}+\frac{\sigma^{2}}{9}, \\
& R_{2}=\frac{\left(D-c_{1}-c_{2}\right)^{2} \beta_{2} \beta_{1}^{2}\left(9 \beta_{2}-8 \theta_{2}^{2}\right)}{\left(9 \beta_{1} \beta_{2}-4 \beta_{2} \theta_{1}^{2}-4 \beta_{1} \theta_{2}^{2}\right)^{2}}+\frac{\sigma^{2}}{9} .
\end{aligned}
$$

For convenience we let $I_{1}^{1}=I_{1}, I_{2}^{1}=I_{2}, p_{1}^{1}=p_{1}, p_{2}^{1}=p_{2}$, $R_{1}^{1}=R_{1}$, and $R_{2}^{1}=R_{2}$.

Strategy 2: $\{$ cooperate + (cooperate, cooperate $)\}$. For this strategy, the two firms cooperate not only on investment but also on price. The decisions on price are formulated as follows:

$$
\begin{aligned}
\max _{p_{1}} R_{1}= & \left(p_{1}+p_{2}-c_{1}-c_{2}\right)\left(D-p_{1}-p_{2}+\theta_{1} I_{1}+\theta_{2} I_{2}+\varepsilon\right) \\
& -\frac{1}{2 \beta_{1} I_{1}^{2}}-\frac{1}{2 \beta_{2} I_{2}^{2}}, \\
\max _{p_{2}} R_{2}= & \left(p_{1}+p_{2}-c_{1}-c_{2}\right)\left(D-p_{1}-p_{2}+\theta_{1} I_{1}+\theta_{2} I_{2}+\varepsilon\right) \\
& -\frac{1}{2 \beta_{1} I_{1}^{2}}-\frac{1}{2 \beta_{2} I_{2}^{2}} .
\end{aligned}
$$

We have

$$
p_{1}+p_{2}=\frac{c_{1}+c_{2}+D+\theta_{1} I_{1}+\theta_{2} I_{2}+\varepsilon}{2} .
$$


In stage one, the objective function is to maximize the expected joint profit of the two firms:

$$
\begin{aligned}
\max _{I_{1}} E\left[R_{1}+R_{2}=\right. & \left(p_{1}+p_{2}-c_{2}-c_{1}\right) \\
& \cdot\left(D-p_{1}-p_{2}+\theta_{1} I_{1}+\theta_{2} I_{2}+\varepsilon\right) \\
& \left.-\frac{1}{2 \beta_{1} I_{1}^{2}}-\frac{1}{2 \beta_{2} I_{2}^{2}}\right], \\
\max _{I_{2}} E\left[R_{1}+R_{2}=\right. & \left(p_{1}+p_{2}-c_{2}-c_{1}\right) \\
& \cdot\left(D-p_{1}-p_{2}+\theta_{1} I_{1}+\theta_{2} I_{2}+\varepsilon\right) \\
& \left.-\frac{1}{2 \beta_{1} I_{1}^{2}}-\frac{1}{2 \beta_{2} I_{2}^{2}}\right] .
\end{aligned}
$$

Substituting (8) into (9), we have

$$
\begin{gathered}
p_{1}+p_{2}=c_{1}+c_{2}+\frac{\varepsilon}{2}+\frac{\left(D-c_{1}-c_{2}\right) \beta_{1} \beta_{2}}{2 \beta_{1} \beta_{2}-\theta_{1}^{2} \beta_{2}-\beta_{1} \theta_{2}^{2}}, \\
I_{1}=\frac{\left(D-c_{1}-c_{2}\right) \theta_{1} \beta_{2}}{2 \beta_{1} \beta_{2}-\theta_{1}^{2} \beta_{2}-\beta_{1} \theta_{2}^{2}}, \quad I_{2}=\frac{\left(D-c_{1}-c_{2}\right) \theta_{2} \beta_{1}}{2 \beta_{1} \beta_{2}-\theta_{1}^{2} \beta_{2}-\beta_{1} \theta_{2}^{2}}, \\
R_{1}+R_{2}=\frac{\left(D-c_{1}-c_{2}\right)^{2} \beta_{1} \beta_{2}}{4 \beta_{1} \beta_{2}-2 \theta_{1}^{2} \beta_{2}-2 \beta_{1} \theta_{2}^{2}}+\frac{\sigma^{2}}{4} .
\end{gathered}
$$

$R_{2}^{2}=R_{2}$.

Let $I_{1}^{2}=I_{1}, I_{2}^{2}=I_{2}, p_{1}^{2}=p_{1}, p_{2}^{2}=p_{2}, R_{1}^{2}=R_{1}$, and

Strategy 3: $\{$ cooperate + (cooperate, compete) $\}$. In this strategy, the two firms cooperate on investment in stage one. In stage two, firm 1 selects price cooperation and firm 2 selects price competition simultaneously. Firm l's objective is to maximize the joint expected profit. Firm 2's objective is to maximize its own profit. The decisions of stage two are formulated as follows:

$$
\begin{aligned}
\max _{p_{1}} R_{1}= & \left(p_{1}+p_{2}-c_{1}-c_{2}\right)\left(D-p_{1}-p_{2}+\theta_{1} I_{1}+\theta_{2} I_{2}\right) \\
& -\frac{1}{2 \beta_{1} I_{1}^{2}}-\frac{1}{2 \beta_{2} I_{2}^{2}}, \\
\max _{p_{2}} R_{2}= & \left(p_{2}-c_{2}\right)\left(D-p_{1}-p_{2}+\theta_{1} I_{1}+\theta_{2} I_{2}\right)-\frac{1}{2 \beta_{2} I_{2}^{2}} .
\end{aligned}
$$

We have

$$
p_{1}=c_{1}, \quad p_{2}=\frac{D+c_{2}-c_{1}+\theta_{1} I_{1}+\theta_{2} I_{2}+\varepsilon}{2} \text {. }
$$

In stage one, the objectives are

$$
\begin{aligned}
\max _{I_{1}} E\left[R_{1}+R_{2}=\right. & \left(p_{1}+p_{2}-c_{2}-c_{1}\right) \\
& \cdot\left(D-p_{1}-p_{2}+\theta_{1} I_{1}+\theta_{2} I_{2}+\varepsilon\right) \\
& \left.-\frac{1}{2 \beta_{1} I_{1}^{2}}-\frac{1}{2 \beta_{2} I_{2}^{2}}\right],
\end{aligned}
$$

$$
\begin{aligned}
\max _{I_{2}} E\left[R_{1}+R_{2}=\right. & \left(p_{1}+p_{2}-c_{2}-c_{1}\right) \\
& \cdot\left(D-p_{1}-p_{2}+\theta_{1} I_{1}+\theta_{2} I_{2}+\varepsilon\right) \\
& \left.-\frac{1}{2 \beta_{1} I_{1}^{2}}-\frac{1}{2 \beta_{2} I_{2}^{2}}\right] .
\end{aligned}
$$

Substituting from (12) into (13) we get

$$
\begin{gathered}
p_{1}=c_{1} ; \quad p_{2}=c_{2}+\frac{\left(D-c_{1}-c_{2}\right) \beta_{1} \beta_{2}}{2 \beta_{1} \beta_{2}-\beta_{2} \theta_{1}^{2}-\beta_{1} \theta_{2}^{2}}+\frac{\varepsilon}{2}, \\
I_{1}=\frac{\left(D-c_{1}-c_{2}\right) \theta_{1} \beta_{2}}{2 \beta_{1} \beta_{2}-\beta_{2} \theta_{1}^{2}-\beta_{1} \theta_{2}^{2}} ; \quad I_{2}=\frac{\left(D-c_{1}-c_{2}\right) \theta_{2} \beta_{1}}{2 \beta_{1} \beta_{2}-\beta_{2} \theta_{1}^{2}-\beta_{1} \theta_{2}^{2}}, \\
R_{1}=-\frac{\left(D-c_{1}-c_{2}\right)^{2} \beta_{1} \beta_{2}^{2} \theta_{1}^{2}}{2\left(2 \beta_{1} \beta_{2}-\beta_{2} \theta_{1}^{2}-\beta_{1} \theta_{2}^{2}\right)^{2}}, \\
R_{2}=\frac{\left(D-c_{1}-c_{2}\right)^{2} \beta_{1}^{2} \beta_{2}\left(2 \beta_{2}-\theta_{2}^{2}\right)}{2\left(2 \beta_{1} \beta_{2}-\beta_{2} \theta_{1}^{2}-\beta_{1} \theta_{2}^{2}\right)^{2}}+\frac{\sigma^{2}}{4} .
\end{gathered}
$$

Let $I_{1}^{3}=I_{1}, I_{2}^{3}=I_{2}, p_{1}^{3}=p_{1}, p_{2}^{3}=p_{2}, R_{1}^{3}=R_{1}$, and $R_{2}^{3}=R_{2}$.

Strategy 4: \{cooperate+(compete, cooperate) $\}$. Different from strategy 3 , in stage two, firm 2 competes and firm 1 cooperates on price. The decisions are formulated as follows:

$$
\begin{aligned}
& \max _{p_{1}} R_{1}=\left(p_{1}-c_{1}\right)\left(D-p_{1}-p_{2}+\theta_{1} I_{1}+\theta_{2} I_{2}+\varepsilon\right)-\frac{1}{2 \beta_{1} I_{1}^{2}} \\
& \max _{p_{2}} R_{2}+R_{1}=\left(p_{1}+p_{2}-c_{1}-c_{2}\right) \\
& \cdot\left(D-p_{1}-p_{2}+\theta_{1} I_{1}+\theta_{2} I_{2}+\varepsilon\right) \\
&-\frac{1}{2 \beta_{1} I_{1}^{2}}-\frac{1}{2 \beta_{2} I_{2}^{2}} .
\end{aligned}
$$

Solving (15), we have

$$
p_{1}=\frac{D+c_{1}-c_{2}+\theta_{1} I_{1}+\theta_{2} I_{2}+\varepsilon}{2}, \quad p_{2}=c_{2}
$$

From (15) the following investment decisions in stage one are made:

$$
\begin{aligned}
\max _{I_{1}} E\left[R_{1}+R_{2}=\right. & \left(p_{1}+p_{2}-c_{2}-c_{1}\right) \\
& \cdot\left(D-p_{1}-p_{2}+\theta_{1} I_{1}+\theta_{2} I_{2}+\varepsilon\right) \\
& \left.-\frac{1}{2 \beta_{1} I_{1}^{2}}-\frac{1}{2 \beta_{2} I_{2}^{2}}\right]
\end{aligned}
$$


TABle 1: A game matrix.

\begin{tabular}{|c|c|c|}
\hline \multirow{2}{*}{ Firm I } & \multicolumn{2}{|c|}{ Firm II } \\
\hline & Cooperate + compete & Cooperate + cooperate \\
\hline Cooperate + compete & $\begin{array}{l}R_{1}^{1}=\frac{\left(D-c_{1}-c_{2}\right)^{2} \beta_{1} \beta_{2}^{2}\left(9 \beta_{1}-8 \theta_{1}^{2}\right)}{\left(9 \beta_{1} \beta_{2}-4 \beta_{2} \theta_{1}^{2}-4 \beta_{1} \theta_{2}^{2}\right)^{2}}+\frac{\sigma^{2}}{9} \\
R_{2}^{1}=\frac{\left(D-c_{1}-c_{2}\right)^{2} \beta_{2} \beta_{1}^{2}\left(9 \beta_{2}-8 \theta_{2}^{2}\right)}{\left(9 \beta_{1} \beta_{2}-4 \beta_{2} \theta_{1}^{2}-4 \beta_{1} \theta_{2}^{2}\right)^{2}}+\frac{\sigma^{2}}{9}\end{array}$ & $\begin{array}{l}R_{1}^{4}=\frac{\left(D-c_{1}-c_{2}\right)^{2} \beta_{1} \beta_{2}^{2}\left(2 \beta_{1}-\theta_{1}^{2}\right)}{2\left(2 \beta_{1} \beta_{2}-\beta_{2} \theta_{1}^{2}-\beta_{1} \theta_{2}^{2}\right)^{2}}+\frac{\sigma^{2}}{4} \\
R_{2}^{4}=\frac{-\left(D-c_{1}-c_{2}\right)^{2} \beta_{1}^{2} \beta_{2} \theta_{2}^{2}}{2\left(2 \beta_{1} \beta_{2}-\beta_{2} \theta_{1}^{2}-\beta_{1} \theta_{2}^{2}\right)^{2}}\end{array}$ \\
\hline Cooperate + cooperate & $\begin{aligned} R_{1}^{3} & =\frac{-\left(D-c_{1}-c_{2}\right)^{2} \beta_{1} \beta_{2}^{2} \theta_{1}^{2}}{2\left(2 \beta_{1} \beta_{2}-\beta_{2} \theta_{1}^{2}-\beta_{1} \theta_{2}^{2}\right)^{2}}, \\
R_{2}^{3} & =\frac{\left(D-c_{1}-c_{2}\right)^{2} \beta_{1}^{2} \beta_{2}\left(2 \beta_{2}-\theta_{2}^{2}\right)}{2\left(2 \beta_{1} \beta_{2}-\beta_{2} \theta_{1}^{2}-\beta_{1} \theta_{2}^{2}\right)^{2}}+\frac{\sigma^{2}}{4}\end{aligned}$ & $\begin{array}{l}R_{1}^{2}=\frac{\left(D-c_{1}-c_{2}\right)^{2} \beta_{1} \beta_{2}}{4 \beta_{1} \beta_{2}-2 \theta_{1}^{2} \beta_{2}-2 \beta_{1} \theta_{2}^{2}}+\frac{\sigma^{2}}{4}-K \\
R_{2}^{2}=K\end{array}$ \\
\hline
\end{tabular}

$$
\begin{aligned}
\max _{I_{2}} E\left[R_{1}+R_{2}=\right. & \left(p_{1}+p_{2}-c_{2}-c_{1}\right) \\
& \cdot\left(D-p_{1}-p_{2}+\theta_{1} I_{1}+\theta_{2} I_{2}+\varepsilon\right) \\
& \left.-\frac{1}{2 \beta_{1} I_{1}^{2}}-\frac{1}{2 \beta_{2} I_{2}^{2}}\right] .
\end{aligned}
$$

Solving and simplifying terms we get

$$
\begin{gathered}
p_{1}=c_{1}+\frac{\varepsilon}{2}+\frac{\left(D-c_{1}-c_{2}\right) \beta_{1} \beta_{2}}{2 \beta_{1} \beta_{2}-\beta_{2} \theta_{1}^{2}-\beta_{1} \theta_{2}^{2}}, \quad p_{2}=c_{2}, \\
I_{1}=\frac{\left(D-c_{1}-c_{2}\right) \theta_{1} \beta_{2}}{2 \beta_{1} \beta_{2}-\beta_{2} \theta_{1}^{2}-\beta_{1} \theta_{2}^{2}}, \quad I_{2}=\frac{\left(D-c_{1}-c_{2}\right) \theta_{2} \beta_{1}}{2 \beta_{1} \beta_{2}-\beta_{2} \theta_{1}^{2}-\beta_{1} \theta_{2}^{2}}, \\
R_{1}=\frac{\left(D-c_{1}-c_{2}\right)^{2} \beta_{1} \beta_{2}^{2}\left(2 \beta_{1}-\theta_{1}^{2}\right)}{2\left(2 \beta_{1} \beta_{2}-\beta_{2} \theta_{1}^{2}-\beta_{1} \theta_{2}^{2}\right)^{2}}+\frac{\sigma^{2}}{4}, \\
R_{2}=-\frac{\left(D-c_{1}-c_{2}\right)^{2} \beta_{1}^{2} \beta_{2} \theta_{2}^{2}}{2\left(2 \beta_{1} \beta_{2}-\beta_{2} \theta_{1}^{2}-\beta_{1} \theta_{2}^{2}\right)^{2}} .
\end{gathered}
$$

Let $I_{1}^{4}=I_{1}, I_{2}^{4}=I_{2}, p_{1}^{4}=p_{1}, p_{2}^{4}=p_{2}, R_{1}^{4}=R_{1}$, and $R_{2}^{4}=R_{2}$.

2.3. Equilibrium. In Table 1, a game matrix is formulated based on aforementioned results. As noted by Table 1, there are two strategic choices in stage two for each player: cooperation or compete. We only got $R_{1}^{2}+R_{2}^{2}$ in strategy 2 from (10). Consequently, a parameter $K\left(0 \leq K \leq R_{1}^{2}+R_{2}^{2}\right)$ is denoted, which represents a reasonable profit distribution scheme. Under the allocations $K$, the two firms profits are $R_{1}^{2}=\left(D-c_{1}-c_{2}\right)^{2} \beta_{1} \beta_{2} /\left(4 \beta_{1} \beta_{2}-2 \theta_{1}^{2} \beta_{2}-2 \beta_{1} \theta_{2}^{2}\right)+\sigma^{2} / 4-K$ and $R_{2}^{2}=K$ separately.

Proposition 1. In a two-stage dynamic game model with simultaneous actions on investment and price for two complementary transport firms, the strategy: \{cooperate + (compete, compete)\} is unique pure strategy Nash equilibrium.
Proof. To prove that the equilibrium is unique, we need to prove the strategy: $\{$ cooperate + (compete, compete) $\}$, that is, investments cooperate in stage one and price competes in stage two for two firms, is a unique dominant strategy. As depicted in Table 1, When the strategy: (cooperate+compete) is given to firm 1, then the dominant strategy for firm 2 is (cooperate + compete).

When the strategy: (cooperate + cooperate) is adopted by firm 1, then the profit of strategy: (cooperate + compete) by firm 2 is

$$
R_{2}^{3}=\frac{\left(D-c_{1}-c_{2}\right)^{2} \beta_{1}^{2} \beta_{2}\left(2 \beta_{2}-\theta_{2}^{2}\right)}{2\left(2 \beta_{1} \beta_{2}-\beta_{2} \theta_{1}^{2}-\beta_{1} \theta_{2}^{2}\right)^{2}}+\frac{\sigma^{2}}{4} .
$$

For any given allocation $K$ to firm 2, comparing strategy 2 and strategy 3 we find

$$
R_{1}^{3}+R_{2}^{3}=R_{1}^{2}+R_{2}^{2}=\frac{\left(D-c_{1}-c_{2}\right)^{2} \beta_{1} \beta_{2}}{4 \beta_{1} \beta_{2}-2 \theta_{1}^{2} \beta_{2}-2 \beta_{1} \theta_{2}^{2}}+\frac{\sigma^{2}}{4} .
$$

Moreover, $R_{1}^{3}<0$ and we have

$$
\frac{R_{2}^{3}}{R_{2}^{2}}=\left(\frac{\left(D-c_{1}-c_{2}\right)^{2} \beta_{1}^{2} \beta_{2}\left(2 \beta_{2}-\theta_{2}^{2}\right)}{2\left(2 \beta_{1} \beta_{2}-\beta_{2} \theta_{1}^{2}-\beta_{1} \theta_{2}^{2}\right)^{2}}+\frac{\sigma^{2}}{4}\right) \cdot K^{-1}>1 \text {. }
$$

That means that $R_{2}^{3}>R_{2}^{2}$. Hence, the strategy: (cooperate + compete) to firm 2 is always a unique dominant strategy in view of the response of firm 1 .

Similar proof is taken and shows the strategy: (cooperate+ compete) is also unique dominant strategy to firm 1 in view of the response of firm 2 .

Consequently, the strategy: \{cooperate + (compete, compete) $\}$ is a unique pure strategy Nash equilibrium.

As indicated in Proposition 1, in the two-stage game, both parties would not insist on cooperation from beginning to end for opportunistic behavior, even cooperative agreement of stage one is reached by both carriers in advance. They always cooperate in particular stage and compete in others; therefore, the coopetition is essentially dynamic with that 
cooperate and compete are emerged alternatively in different situations.

From reaction functions (2), the prices are strategic substitutes $\left(\partial p_{i} / \partial p_{j}\right)<0$ and the prices for investments are strategic complements $\left(\partial p_{i} / \partial I_{j}\right)>0$. An increase in its own or opponent investment gives the reaction functions a positive shift, while increasing opponent price has opposite effect. We further denote a sensitivity coefficient of investment $\mu_{i}=\theta_{i} / \beta_{i}(i=1,2)$, which measures the sensitivity of investment on demand and on investment cost. Meanwhile, we find $I_{1} / I_{2}=\mu_{1} / \mu_{2}$, which implies that the decisions on investment depend on their sensitivity of investment, if investment by separate firms is more sensitive to demand than to cost and the firm will select higher investments. After considering the given price elastic, the rate $\mu_{1} / \mu_{2}$ can also be used to measure the degree of complementarity between the transport services offered by the two firms. Under the competition setting, some studies have been done on the degree of complementarity [9, 16-18], but all focus on calculating parameters by comparing different commodity's output, rarely focus on the complementary degree of complementary elements for one commodity. In intermodal market, the transport services are provided by successive segments transport services and the shipping fare consists of segments transport fares; therefore, the services are perfect complements. However, after considering investment, the services are not always perfect complements. The degree of complementarity is influenced by investment elasticity not only to demand but to total investment cost.

The equilibrium price (see (6)) is composed of three parts. The first part is marginal cost, the second part is marginal profit, and the third part is risk compensation of demand uncertainty. In the equilibrium the two firms have identical marginal profit and risk compensation. We also note from Table 1 that the level of demand uncertainty of equilibria is $\sigma^{2} / 9$ and other strategies are $\sigma^{2} / 4$. The expected profit of the two separate firms of equilibria is the least affected from demand uncertainty. Hence, coopetition will help to reduce the impact of uncertainty for both parties substantially.

At the beginning of the paper, we assume the two parties are rational and cooperate in investment; that is, the objective is to maximize joint expected profit in stage one. Next we are going to testify if both parties really want to cooperate in stage one.

As contrast with equilibrium, we consider a new strategy 5: $\{$ compete + (compete, compete) , which means the two firms compete not only on investment but also on price. That is a perfect competition setting. Without loss of generality, the same information structure for two stages as aforementioned is considered. Using backward induction approach to analyze the two-stage dynamic model, in stage two, the price decisions are formulated as follows:

$$
\begin{aligned}
& \max _{p_{1}} R_{1}=\left(p_{1}-c_{1}\right)\left(D-p_{1}-p_{2}+\theta_{1} I_{1}+\theta_{2} I_{2}+\varepsilon\right)-\frac{1}{2 \beta_{1} I_{1}^{2}}, \\
& \max _{p_{2}} R_{2}=\left(p_{2}-c_{2}\right)\left(D-p_{1}-p_{2}+\theta_{1} I_{1}+\theta_{2} I_{2}+\varepsilon\right)-\frac{1}{2 \beta_{2} I_{2}^{2}} .
\end{aligned}
$$

We have

$$
\begin{aligned}
& p_{1}=\frac{2 c_{1}-c_{2}+D+I_{1} \theta_{1}+I_{2} \theta_{2}+\varepsilon}{3} ; \\
& p_{2}=\frac{2 c_{2}-c_{1}+D+I_{1} \theta_{1}+I_{2} \theta_{2}+\varepsilon}{3} .
\end{aligned}
$$

And the decisions in stage one are

$$
\begin{aligned}
\max _{I_{1}} E\left[R_{1}+R_{2}=\right. & \left(p_{1}+p_{2}-c_{1}-c_{2}\right) \\
& \cdot\left(D-p_{1}-p_{2}+\theta_{1} I_{1}+\theta_{2} I_{2}+\varepsilon\right) \\
& \left.-\frac{1}{2 \beta_{1} I_{1}^{2}}-\frac{1}{2 \beta_{2} I_{2}^{2}}\right], \\
\max _{I_{2}} E\left[R_{1}+R_{2}=\right. & \left(p_{1}+p_{2}-c_{1}-c_{2}\right) \\
& \cdot\left(D-p_{1}-p_{2}+\theta_{1} I_{1}+\theta_{2} I_{2}+\varepsilon\right) \\
& \left.-\frac{1}{2 \beta_{1} I_{1}^{2}}-\frac{1}{2 \beta_{2} I_{2}^{2}}\right] .
\end{aligned}
$$

Solving and simplifying terms we get

$$
\begin{aligned}
& I_{1}=\frac{2\left(D-c_{1}-c_{2}\right) \theta_{1} \beta_{2}}{9 \beta_{1} \beta_{2}-2 \beta_{2} \theta_{1}^{2}-2 \beta_{1} \theta_{2}^{2}} ; \\
& I_{2}=\frac{2\left(D-c_{1}-c_{2}\right) \beta_{1} \theta_{2}}{9 \beta_{1} \beta_{2}-2 \beta_{2} \theta_{1}^{2}-2 \beta_{1} \theta_{2}^{2}}, \\
& p_{1}=c_{1}+\frac{3\left(D-c_{1}-c_{2}\right) \beta_{1} \beta_{2}}{9 \beta_{1} \beta_{2}-2 \beta_{2} \theta_{1}^{2}-2 \beta_{1} \theta_{2}^{2}}+\frac{\varepsilon}{3} ; \\
& p_{2}=c_{2}+\frac{3\left(D-c_{1}-c_{2}\right) \beta_{1} \beta_{2}}{9 \beta_{1} \beta_{2}-2 \beta_{2} \theta_{1}^{2}-2 \beta_{1} \theta_{2}^{2}}+\frac{\varepsilon}{3}, \\
& R_{1}=\frac{\left(D-c_{1}-c_{2}\right)^{2} \beta_{1} \beta_{2}^{2}\left(9 \beta_{1}-2 \theta_{1}^{2}\right)}{\left(9 \beta_{1} \beta_{2}-2 \beta_{2} \theta_{1}^{2}-2 \beta_{1} \theta_{2}^{2}\right)^{2}}+\frac{\sigma^{2}}{9} ; \\
& R_{2}=\frac{\left(D-c_{1}-c_{2}\right)^{2} \beta_{2} \beta_{1}^{2}\left(9 \beta_{2}-2 \theta_{2}^{2}\right)}{\left(9 \beta_{1} \beta_{2}-2 \beta_{2} \theta_{1}^{2}-2 \beta_{1} \theta_{2}^{2}\right)^{2}}+\frac{\sigma^{2}}{9} .
\end{aligned}
$$

Let $I_{1}^{5}=I_{1}, I_{2}^{5}=I_{2}, p_{1}^{5}=p_{1}, p_{2}^{5}=p_{2}, R_{1}^{5}=R_{1}$, and $R_{2}^{5}=R_{2}$.

It is easy to find that $I_{1}^{5}<I_{1}^{1}, I_{2}^{5}<I_{2}^{1}, p_{1}^{5}<p_{1}^{1}, p_{2}^{5}<p_{2}^{1}$ by comparing (25) with (6). However, we cannot compare $R_{1}^{5}$ with $R_{1}^{1}, R_{2}^{1}$ with $R_{2}^{5}$ in direct. After considering the transport market with symmetric firms and let $\beta_{1}=\beta_{2}=\beta, \theta_{1}=\theta_{2}=$ $\theta$, we get $R_{1}^{5}<R_{1}^{1}, R_{2}^{5}<R_{2}^{1}$. Apparently, both parties will benefit from coopetition. Based on the analyzing above, we summarize the following proposition.

Proposition 2. In a two-stage dynamic game model with simultaneous actions on investment and price for two complementary symmetric transport firms, the investment is positively 
correlated to the sensitivity coefficient of investment. Both parties have motivation to cooperation in investment.

Proposition 2 shows that, apart from price, in the oneshot market game, investment is another complementary element. The degree of complementarity can be measured by sensitivity coefficient of separate firms. Moreover, even without the restriction of contracts or regulations, coopetition aims always exist innately because of the existing of complementary elements which are underlying incentive for either firm to pursue higher return by increasing joint profit.

2.4. Extend Analysis. Furthermore, from Table 1, such following equalities and inequality are held; that is, $R_{1}^{2}+R_{2}^{2}=$ $R_{1}^{3}+R_{2}^{3}=R_{1}^{4}+R_{2}^{4}>R_{1}^{1}+R_{2}^{1}$. That implies that the final coopetition equilibrium: $\{$ cooperate + (compete, compete) is not Pareto efficiency and the two firms are in prisoner's dilemma. We already knew from game theory [19] the perfect cooperation cannot be realized in the competition market. Hence, strategy 2 is not easy to attain. For the strategy 3 and strategy 4 , we find even either party who unilateral deviates cooperate would obtains excess return and another party thus gets minus return (In certain cases, one firm sets low price (equals marginal cost) that will facilitate to enlarge the "pie" of market. That is a kind of cooperate to enlarge system benefits by sacrificing partial benefits.) for inequalities $R_{1}^{4}\left(R_{2}^{3}\right)>R_{1}^{2}+$ $R_{2}^{2}, R_{1}^{3}<0$ and $R_{2}^{4}<0$ holding, but the total system profits are then improved $\left(R_{1}^{2}+R_{2}^{2}=R_{1}^{3}+R_{2}^{3}=R_{1}^{4}+R_{2}^{4}>R_{1}^{1}+R_{2}^{1}\right)$. That implies new equilibrium (strategy 3 or 4 ) with higher efficiency would be realized to substitute initial equilibrium (strategy 1) by setting suitable incentives.

For the strategy 3 (strategy 4), firm 1 (firm 2) that selects price cooperation would set price according to his marginal cost, at the same time the excess benefits would be gained by firm 2 (firm 1) for deviating price cooperation unilaterally to set higher price. Assume both firms reach agreement on allocation $W$, either firm which earn excess benefits would compensate $W$ to the partner's cooperation behaviors. The payoffs of two firms in strategy 3 and 4 are changed as follows, and then we have Proposition 3:

$$
\begin{aligned}
& R_{1}^{3 \prime}=W-\frac{\left(D-c_{1}-c_{2}\right)^{2} \beta_{1} \beta_{2}^{2} \theta_{1}^{2}}{2\left(2 \beta_{1} \beta_{2}-\beta_{2} \theta_{1}^{2}-\beta_{1} \theta_{2}^{2}\right)^{2}} ; \\
& R_{2}^{3 \prime}=\frac{\left(D-c_{1}-c_{2}\right)^{2} \beta_{1}^{2} \beta_{2}\left(2 \beta_{2}-\theta_{2}^{2}\right)}{2\left(2 \beta_{1} \beta_{2}-\beta_{2} \theta_{1}^{2}-\beta_{1} \theta_{2}^{2}\right)^{2}}+\frac{\sigma^{2}}{4}-W, \\
& R_{1}^{4 \prime}=\frac{\left(D-c_{1}-c_{2}\right)^{2} \beta_{1} \beta_{2}^{2}\left(2 \beta_{1}-\theta_{1}^{2}\right)}{2\left(2 \beta_{1} \beta_{2}-\beta_{2} \theta_{1}^{2}-\beta_{1} \theta_{2}^{2}\right)^{2}}+\frac{\sigma^{2}}{4}-W ; \\
& R_{2}^{4 \prime}=-\frac{\left(D-c_{1}-c_{2}\right)^{2} \beta_{1}^{2} \beta_{2} \theta_{2}^{2}}{2\left(2 \beta_{1} \beta_{2}-\beta_{2} \theta_{1}^{2}-\beta_{1} \theta_{2}^{2}\right)^{2}}+W .
\end{aligned}
$$

Proposition 3. In the investment and pricing two-stage game with simultaneous actions, if the two firms reach agreement on allocation $W$ in advance and when the conditions $R_{2}^{4 \prime}>R_{2}^{1}, R_{2}^{3 \prime}>R_{2}^{2}, R_{1}^{3 \prime}>R_{1}^{1}, R_{1}^{4 \prime}>R_{1}^{2}$ are satisfied, then the strategies: $\{$ cooperate + (cooperate, compete $)\}$ and $\{$ cooperate $+($ compete, cooperate $)\}$ are two Nash equilibriums.

Proof. First we assume the two firms reach following agreement: both parties commit price cooperation; otherwise either firm who unilateral deviates cooperation will compensate $W$ to another firm.

Next we calculate the new Nash equilibriums based on the assumptions.

When condition $R_{2}^{4 \prime}>R_{2}^{1}$ holds, for the given strategy: (cooperate + compete) to firm 1 then strategy: (cooperate + cooperate) is dominant strategy to firm 2 . When firm 1 selects strategy: (cooperate + cooperate) then strategy: (cooperate + compete) is the dominant strategy to firm 2 for $R_{2}^{3 \prime}>R_{2}^{2}$ holding.

Similarly, when firm 2 selects strategy: (cooperate + compete) then strategy: (cooperate + cooperate) is dominant strategy to firm 1 for $R_{1}^{3 \prime}>R_{1}^{1}$ holding. When firm 2 selects strategy: (cooperate + cooperate) then strategy: (cooperate + compete) is the dominant strategy to firm 1 for $R_{1}^{4 \prime}>R_{1}^{2}$ holding.

Therefore equilibriums \{cooperate + (cooperate, compete) $\}$ and $\{$ cooperate + (compete, cooperate $)\}$ are two Nash equilibriums in the game.

Proposition 3 shows the following.

(1) Under the competition setting, setting low price (generally, the marginal cost of transport service is very low. Corresponding studies see Mayeres et al. [20], Jara-Diaz et al. [21], and Voltes-Dorta and Lei [22]) at their marginal cost and reaching an agreement on allocation $W$ are two kinds of cooperation behaviors to two separate firms. That implies that if more cooperation is taken into consideration by both firms, the original unique pure Nash equilibrium would be replaced with new equilibriums, those are new sorts of coopetition with higher system efficiency. Therefore, the natures of coopetition are diversity and potential, dynamic, and very broad in scope.

(2) The system Pareto efficiency would be realized for existing of new multiple Nash equilibrium after setting suitable allocations. As long as both firms agree on the allocation $W$, the new coopetition would benefit both parties. Comparing with the traditional winlose scenarios, the new coopetition is looking for winwin scenarios in which firms strive to enlarge the size of the total pie which they can divide up. Meanwhile, how to design a suitable inventive mechanism will be a new critical issue.

\section{Evolution of Coopetition}

From the prospective of life cycle, the infrastructure investment always occurs at a certain time and advances to the price stage. Actually one-shot game is a rare occurrence in reality; the repeated interactions on pricing are always happen after investment stage. In this section, the finite and 
infinite repeated pricing game will be explored to study the equilibrium and the evolution of coopetition.

3.1. Finitely Repeated Pricing Game. Based on the results of aforementioned two-stage game, we first consider a finitely repeated pricing game with simultaneous actions in every stage. That means the cooperative investment decision is made firstly and then the repeated pricing decisions are made for finite time horizon subsequently. In reality, the repeated game is always played with finite time horizon. Based on the fork theorem [19], we have learned if stage game had unique Nash equilibrium then finitely repeated game had unique subgame perfect Nash equilibrium (SPNE). Moreover, the SPNE is just the repetition of the stage game Nash equilibrium. Therefore, as discussed in Section 2.3, the repetitive price competition for two firms is a unique SPNE with low efficiency.

Next we will discuss the nature of the specific SPNE with higher efficiency. From the result of Proposition 3, we knew that, under setting the suitable allocation $W$, the new multiple Nash equilibrium with higher efficiency that is, strategies: $\{$ cooperate + (cooperate, compete) $\}$ and $\{$ cooperate + (compete, cooperate) $\}$ are then attained, where pricing strategy: (cooperation, competition) and (competition, cooperation) are multiple stage game Nash equilibrium. Considering the finitely repeated pricing game with simultaneous actions, lots of SPNE paths are formulated for the existing of multiple stage game Nash equilibrium. That includes repeating strategies of (cooperate, compete), (compete, cooperate), and alternately selecting cooperation and competition by two firms. For the sake of fairness, we consider the SPNE route that both firms select cooperation and competition alternately in each stage. The following two strategies are SPNE; that is, \{(investment cooperation + price cooperation + price competition + price cooperation + $\cdots$ ), (investment cooperation + price competition + price cooperation + price competition $+\cdots)\}$ and (investment cooperation + price competition + price cooperation + price competition $+\cdots$ ), (investment cooperation + price cooperation + price competition + price cooperation, $+\cdots)\}$ are SPNE (different from the "tit-for-tat" strategy in prisoner's dilemma repeated game [19], in this paper, both firms select cooperation and competition alternately are SPNE, however, "tit-for-tat" strategy is not SPNE). Some results are summarized as Proposition 4.

Proposition 4. For the given SPNE with alternate selecting price cooperation and price competition for two firms, the preferred price strategy to the first stage is affected by repeated periodst.

(i) When repeated periods $t$ is an odd number, the sequence to choosing price competition and price cooperation is immaterial. The final total profits are $M_{1} t / 2$ and $M_{2} t / 2$ to two firms separately.

(ii) When repeated periods t are an even number, if the final price stage game Nash equilibrium is that firm 1 chooses price competition and firm 2 chooses price cooperation, then the final profits to both firms are $M_{1}(t-1) / 2+R_{1}^{4 \prime}$ and $M_{2}(t-1) / 2+R_{2}^{4 \prime}$. Otherwise, if price stage game Nash equilibrium is that firm 1 choose price cooperation and firm 2 choose price competition, the final total profits are $M_{1}(t-1) / 2+R_{1}^{3 \prime}$ and $M_{2}(t-1) / 2+R_{2}^{3 \prime}$ to two firms separately,

where $R_{1}^{4 \prime}+R_{1}^{3 \prime}=M_{1}, R_{2}^{4 \prime}+R_{2}^{3 \prime}=M_{2}$.

Proof. Based on Proposition 3, the strategy that two firms alternately select price cooperation and price competition at stage game is SPNE. After taking into account individual rationality the conditions $R_{1}^{4 \prime}>R_{1}^{3 \prime}$ or $R_{2}^{3 \prime}>R_{2}^{4 \prime}$ are satisfied, assuming $R_{1}^{4 \prime}+R_{1}^{3 \prime}=M_{1}, R_{2}^{4 \prime}+R_{2}^{3 \prime}=M_{2}$; then the oddeven character of repeated periods $t$ would impact the first best strategy for both parties' stage game.

When repeated periods $t$ are an even number, the sequence of pricing strategy in stage game to separate firm is immaterial. The final individual profit of separate firm's is $M_{i} t / 2,(i=1,2)$ regardless of the one who chooses competition strategy and the other who choose cooperation at the first stage game.

When repeated periods $t$ are an odd number, two firms consider the difference between strategies 3 and 4; the sequence on selecting price competition or price cooperation will impact their individual final profit in direct.

If the first price stage game equilibrium is (compete, cooperate) then firm l's profit in the given SPNE is $M_{1}(t-$ 1) $/ 2+R_{1}^{4 \prime}$, and firm 2's profit in the given SPNE is $M_{2}(t-$ 1) $/ 2+R_{2}^{4 \prime}$. Otherwise, if price stage game Nash equilibrium is (cooperate, compete) then firm 1's profit is $M_{1}(t-1) / 2+R_{1}^{3 \prime}$, and firm 2's profit is $M_{2}(t-1) / 2+R_{2}^{3 \prime}$.

Proposition 4 shows that the final SPNE is a dynamic and complicated coopetition, which further extends the perspective that the natures of coopetition are diversity and potential, dynamic, and very broad in scope. On the one hand, under setting the suitable allocation scheme both parties will escape the prisoners' dilemma challenge even by finitely repeated pricing game, but on the other the new conflict will emerge for the changing of repeated periods $t$. Either firm will select stage game equilibrium of advantage for themselves. Moreover, the offering sequence will depend on their individual market power and especially depend on exogenic force such as bargaining power. Meanwhile, setting the effective negotiation mechanism is necessary to improve cooperation.

3.2. Infinitely Repeated Game. In this section, we consider a repeated price game with infinite time horizon. As depicted in Table 1 , the pure strategy Nash equilibrium of basic two-stage game with simultaneous actions is coopetition strategy 1 : \{investment cooperation + price (competition, competition)\}, which is not system Pareto efficiency for holding that $R_{1}^{2}+R_{2}^{2}>R_{1}^{1}+R_{2}^{1}$. Different from strategy 1 , the strategy 2 implies perfect cooperation with Pareto efficiency; therefore, our aim is how to make perfect cooperation a SPNE.

Without loss of generality, assuming the two firms have the same discount rate $\delta(0 \leq \delta \leq 1)$, which measures 
their patience in the repeated game. $K$ denotes the joint profit allocation to firm 2. As we have known from fork theorem [19] that if players are patient enough then SPNE can achieve "any" reasonable payoffs.

Designing such following trigger strategy: from the first period of price repeated game, the two firms play price cooperation strategy unconditionally, if both parties play cooperation strategy until the $t-1$ period then any firm will continue to play cooperation strategy, or else one firm who cooperates at $t-1$ period will deviate to play competition from $t$ phase and last forever.

Proposition 5. In the investment and infinitely repeated pricing game, for a given discount rate $\delta(0 \leq \delta \leq 1)$, if inequalities $(i)(M-K) /(1-\delta)>R_{1}^{4}+R_{1}^{1} \delta /(M-K) /(1-\delta)$ and (ii) $K /(1-\delta)>R_{2}^{3}+R_{2}^{1} \delta /(1-\delta)$ are satisfied, then the perfect cooperation strategy: \{Investment cooperation + price cooperation per period $\}$ will be chosen by both parties, that is, SPNE.

Proof. We first deduce the sufficient conditions which stimulate two firms to choose cooperation simultaneously at each stage game, that is, SPNE. Without loss of generality, assume the two firms have same discount rate $\delta(0 \leq \delta \leq 1)$ and $R_{1}^{2}+R_{2}^{2}=M$.

There are two kinds of subgames: (1) subgame following a history in which no firm has ever price competition; (2) any other game.

For case (1) suppose up to period $t$, the strategy price competition has never been played, firm $i$ 's $(i=1,2)$ payoff looking forward are as follows.

Play price cooperation: firm 1's profit is $M-K+(M-K) \delta+$ $\cdots=(M-K) /(1-\delta)$, and firm 2's profit is $K /(1-\delta)$. When firm 1 unilateral deviates cooperation then its profit is $R_{1}^{4}+$ $R_{1}^{1} \delta /(1-\delta)$. Therefore, when $(M-K) /(1-\delta)>R_{1}^{4}+R_{1}^{1} \delta /(1-\delta)$, the deviation is not profitable to firm 1 . When firm 2 unilateral deviates cooperation then its profit is $R_{2}^{3}+R_{2}^{1} \delta /(1-\delta)$. When the condition $K /(1-\delta)>R_{2}^{3}+R_{2}^{1} \delta /(1-\delta)$ is satisfied then firm 2 would never first unilateral deviate cooperation to choose competition.

For case (2) price competition is played at certain period before $t$, since (price competition, price competition) is the Nash equilibrium of the static game; meanwhile, there is no profitable deviation for any discount rate $\delta(0 \leq \delta \leq 1)$.

Therefore, under setting the trigger strategy, the strategy: \{investment cooperation + price cooperation per period $\}$ is SPNE.

Proposition 5 shows that under the incentive of given trigger strategy, both firms have no motivation to deviate cooperation unilaterally. The perfect cooperation with Pareto efficiency will be SPNE. Meanwhile, any gains from opportunistic behaviors are trivial. All participants wish not only to cooperate, but also to penalize any deviate behaviors.

\section{Numerical Study}

We introduce a numerical example to simulate the formation and characteristics of coopetition in intermodal industry.

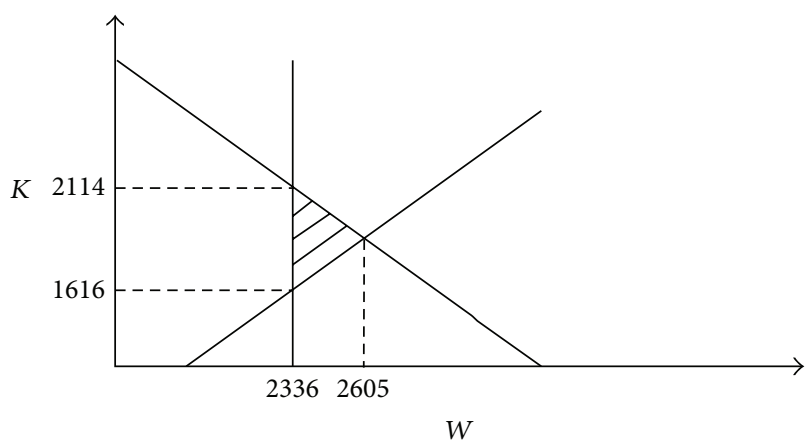

FIGURE 2: Appropriate allocation.

As depicted in Figure 1, we adopt the same scenario as in Section 2.1. There are two transport firms with complementary transport modal to develop intermodal services. After considering investment and price, a two-stage game modal with simultaneous actions is played between the two firms. All parameters are given: $D=120, c_{1}=8, c_{2}=6, \varepsilon \sim$ $N\left(0,10^{2}\right), \beta_{1}=1, \beta_{2}=0.9, \theta_{1}=0.5$, and $\theta_{2}=0.5$.

Firstly, a two-stage basic game with simultaneous actions on investment and pricing decisions is played. It is easy to prove the strategy: \{investment cooperation + price (competition, competition) $\}$ is a unique pure Nash equilibrium. That implies that both parties would not cooperate completely and coopetition is the final equilibrium. All those are consistent with the conclusions of Proposition 1.

It is easy to know that the realized equilibrium is low system efficiency. Assuming the two firms agree on such allocation which either firm whose unilateral deviates cooperation will pay $W$ to the other. Therefore, we have $R_{1}^{4 \prime}=$ $4561-W, R_{2}^{4 \prime}=W-720, R_{1}^{3}=W-648$, and $R_{2}^{3}=4489-W$. After calculation we get the following solution set $\{(K, W) \mid$ $W+K<4489, W-K<720, W>2336\}$. As described in Figure 2, the shaded area is the feasible domain, in which strategies 3 and 4 are new Nash equilibrium. Further analysis shows that all of them are new kinds of coopetition.

We further explore the complexity and evolution of coopetition by finitely repeated game. Defining $K=1800$ and $W=2400$, the strategy of alternating offer cooperation and competition by two firms would be a SPNE. When repeated periods $t$ is an odd number, let $t=2$; whatever any firm first selects as a price competition strategy, their final profits are 3913 and 3769 separately. When repeated periods $t$ are an even number, let $t=3$; any firm who has more bargaining power in market will first select price competition at the first stage and therefore benefit more in the repeated game. If firm 1 has more bargaining power, then price competition strategy is to be preferred to firm 1; the final stage equilibrium $(6074,5449)$ for two firms would be reached. Otherwise, firm 2 first chooses price competition in stage one of price repeated game, the final stage equilibrium are $(5665,5858)$.

Those results testify the conclusions of Propositions 3 and 4 and show that the natures of coopetition are diversity and potential, dynamic, and very broad in scope. The new coopetition with higher efficiency would be realized by designing 
suitable allocation scheme. During the finitely repeated game process, the sequence of alternating offer would correlate with the repeated periods and separate firm's bargaining power in market.

Finally, let $M=3841$ and $K=1800$; after calculation, we can know when discount rate $\delta$ satisfies $0.6<\delta<1$, then perfect cooperation in each stage game is SPNE. Both parties never deviate from cooperation under the incentive of trigger strategy. The results testify the valid of Proposition 5.

\section{Conclusions}

In this paper, a coopetition behavior analysis of the downstream separate carriers in intermodal freight services chain is studied. Our primary objective is to explore the basic theory concerning cooperation and competition behavior in intermodal freight market. We consider nature of cooperation between firms in making investments to improve demand potential, as well as the competition between firms in making their pricing decisions. After considering different information structure and the level of uncertainty in the market, a basic two-stage dynamic game model on cooperation investment and price strategies with simultaneous actions is first formulated, and repeated game with infinite periods and finite periods are then analyzed, respectively. Our results can be summarized as follows.

(i) In the basic two-stage game, the coopetition strategy: \{investment cooperate + price (compete, compete) is unique pure strategy Nash equilibrium, both parties have motivation to select coopetition even if the agreement for cooperation investment has been reached in advance.

(ii) Under setting the suitable allocation $W$ the new Nash equilibriums with higher efficiency would be emerged. Those are new kinds of coopetition.

(iii) During the finitely repeated game the strategy of alternating price competition by two firms is SPNE, the sequence of choosing competition would be affected by repeated periods. When repeated periods are an even number, the sequence of which one first choosing price competition for stage game is immaterial. Otherwise, either firm who compete firstly will depends on their individual bargaining power in the market.

(iv) For the infinitely repeated game the investment cooperation and subsequent price cooperation in every stage game is SPNE by setting suitable trigger strategy.

Our analysis indicates the interactions between two firms with complementary transport services are not simplex cooperation or competition, but a kind of new complex relationship of alternate cooperation and competition, that is, coopetition. In the equilibrium state both two firms will increase profit and decrease the effect of the demand uncertainty. Meanwhile, we observe if either firm insists price cooperation regardless of unilateral deviating by the opponents, then the opponents not only can get free ride but also Pareto efficiency of the total system is therefore realized. However, such strategies are not Nash equilibrium; either firm has no motivation to deviate competition unless setting suitable incentives. By setting suitable allocation the new coopetition with higher efficiency would be realized. That implies the coopetition is diversity and potential, dynamic, and very broad in scope.

The further study shows that, even in the finitely repeated pricing game, both firms have incentive to reach a tacit understanding to alternate choosing price cooperation and competition after setting suitable allocation scheme. As the factor of exogenous the repeated periods $t$ is then going to be an issue; the higher profit will lead to competition preferences for two firms. When repeated periods $t$ is an odd number, the decisions are affected by their individual bargaining power in market. As such, the nature of competition between firms affects the level of cooperation they provide to each other. The more the cooperation considered by separate firms is, the more it will facilitate the realization of collective rationality. In infinitely repeated pricing game, after satisfying conditions the trigger strategy is a SPNE. Meanwhile, any gains from opportunistic behaviors are trivial. All participants have willingness not only to build a reputation on cooperation, but also to penalize any deviate behaviors.

The contribution of this paper is to study the complexity and evolution of coopetition by two firms' game. In future research, we plan to study the optimal form of coopetition including the bargaining power or information asymmetry in cost.

\section{Conflict of Interests}

The authors declare that there is no conflict of interests regarding the publication of this paper.

\section{Acknowledgments}

The authors would like to thank the two anonymous referees for helpful comments. This research was supported in part by the Natural Sciences Foundation of China under Grant 61164003 and 71271178.

\section{References}

[1] P. T. Cherington, Advertising as a Business Force: A Compilation of Experiences, Ayer Company Publishers, Manchester, NH, USA, 1976.

[2] A. M. Brandburger and B. J. Nalebuff, Co-Opetition, Doubleday Currency, New York, NY, USA, 1996.

[3] B. A. Pasternack, "Optimal pricing and the return policy for perishable commodities," Marketing Science, vol. 4, no. 2, pp. 166-176, 1985.

[4] G. P. Cachon and A. G. Kök, "Competing manufacturers in a retail supply chain: on contractual form and coordination," Management Science, vol. 56, no. 3, pp. 571-589, 2010.

[5] G. P. Cachon and M. A. Lariviere, "Supply chain coordination with revenue-sharing contracts: strengths and limitations," Management Science, vol. 51, no. 1, pp. 30-44, 2005. 
[6] S. K. Mukhopadhyay, X. Yue, and X. Zhu, "A Stackelberg model of pricing of complementary goods under information asymmetry," International Journal of Production Economics, vol. 134, no. 2, pp. 424-433, 2011.

[7] H. Gurnani, M. Erkoc, and Y. Luo, "Impact of product pricing and timing of investment decisions on supply chain coopetition," European Journal of Operational Research, vol. 180, no. 1, pp. 228-248, 2007.

[8] C. Macharis and Y. M. Bontekoning, "Opportunities for OR in intermodal freight transport research: a review," European Journal of Operational Research, vol. 153, no. 2, pp. 400-416, 2004.

[9] D. J. Clark, F. Jørgensen, and T. A. Mathisen, "Competition in complementary transport services," Transportation Research Part B: Methodological, vol. 60, no. 1, pp. 146-159, 2014.

[10] A. Zhang, C. Lang, Y. V. Hui, and L. Leung, "Intermodal alliance and rivalry of transport chains: the air cargo market," Transportation Research Part E: Logistics and Transportation Review, vol. 43, no. 3, pp. 234-246, 2007.

[11] J. Liu, J. Yu, and Y. Li, "Coordination game analysis through penalty scheme in freight intermodal service," Mathematical Problems in Engineering, vol. 2012, Article ID 247509, 14 pages, 2012.

[12] S. Peeta and S. Hernandez, Modeling of collaborative less-thantruckload carrier freight networks, 2011, http://www.purdue .edu/discoverypark/nextrans/assets/pdfs/Year\%202\%20Final\% 20Reports/Final\%20Report\%20042.pdf.

[13] P. S. Desai and K. Srinivasan, "A franchise management issue: demand signaling under unobservable service," Management Science, vol. 41, no. 10, pp. 1608-1623, 1995.

[14] P. S. Desai, "Advertising fee in business-format franchising," Management Science, vol. 43, no. 10, pp. 1401-1419, 1997.

[15] X. H. Yue, S. K. Mukhopadhyay, and X. W. Zhu, "A Bertrand model of pricing of complementary goods under information asymmetry," Journal of Business Research, vol. 59, no. 10-11, pp. 1182-1192, 2006.

[16] J. C. Bárcena-Ruiz and M. P. Espinosa, "Should multiproduct firms provide divisional or corporate incentives?" International Journal of Industrial Organization, vol. 17, no. 5, pp. 751-764, 1999.

[17] N. Singh and X. Vives, "Price and quantity competition in a differentiated duopoly," The RAND Journal of Economics, vol. 15, no. 4, pp. 546-554, 1984.

[18] D. J. Clark, F. Jørgensen, and T. A. Mathisen, "Relationships between fares, trip length and market competition," Transportation Research Part A: Policy and Practice, vol. 45, no. 7, pp. 611624, 2011.

[19] D. Fudenberg and J. Tirole, Game Theory, MIT Press, Cambridge, Mass, USA, 1991.

[20] I. Mayeres, S. Ochelen, and S. Proost, "The marginal external costs of urban transport," Transportation Research Part D: Transport and Environment, vol. 1, no. 2, pp. 111-130, 1996.

[21] S. R. Jara-Diaz, P. P. Donoso, and J. A. Araneda, "Estimation of marginal transport costs: the flow aggregation function approach," Journal of Transport Economics and Policy, vol. 26, no. 1, pp. 35-48, 1992.

[22] A. Voltes-Dorta and Z. Lei, "The impact of airline differentiation on marginal cost pricing at UK airports," Transportation Research Part A: Policy and Practice, vol. 55, pp. 72-88, 2013. 


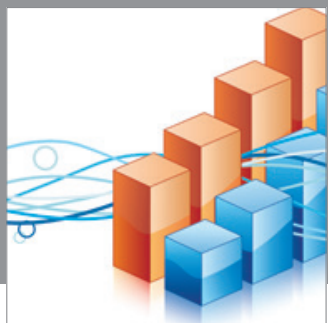

Advances in

Operations Research

mansans

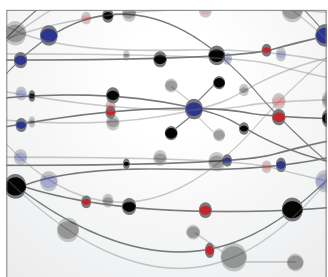

The Scientific World Journal
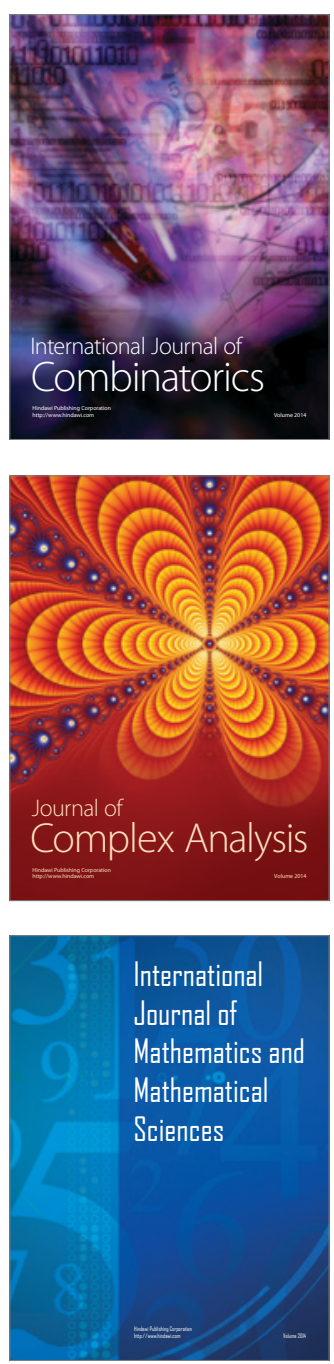
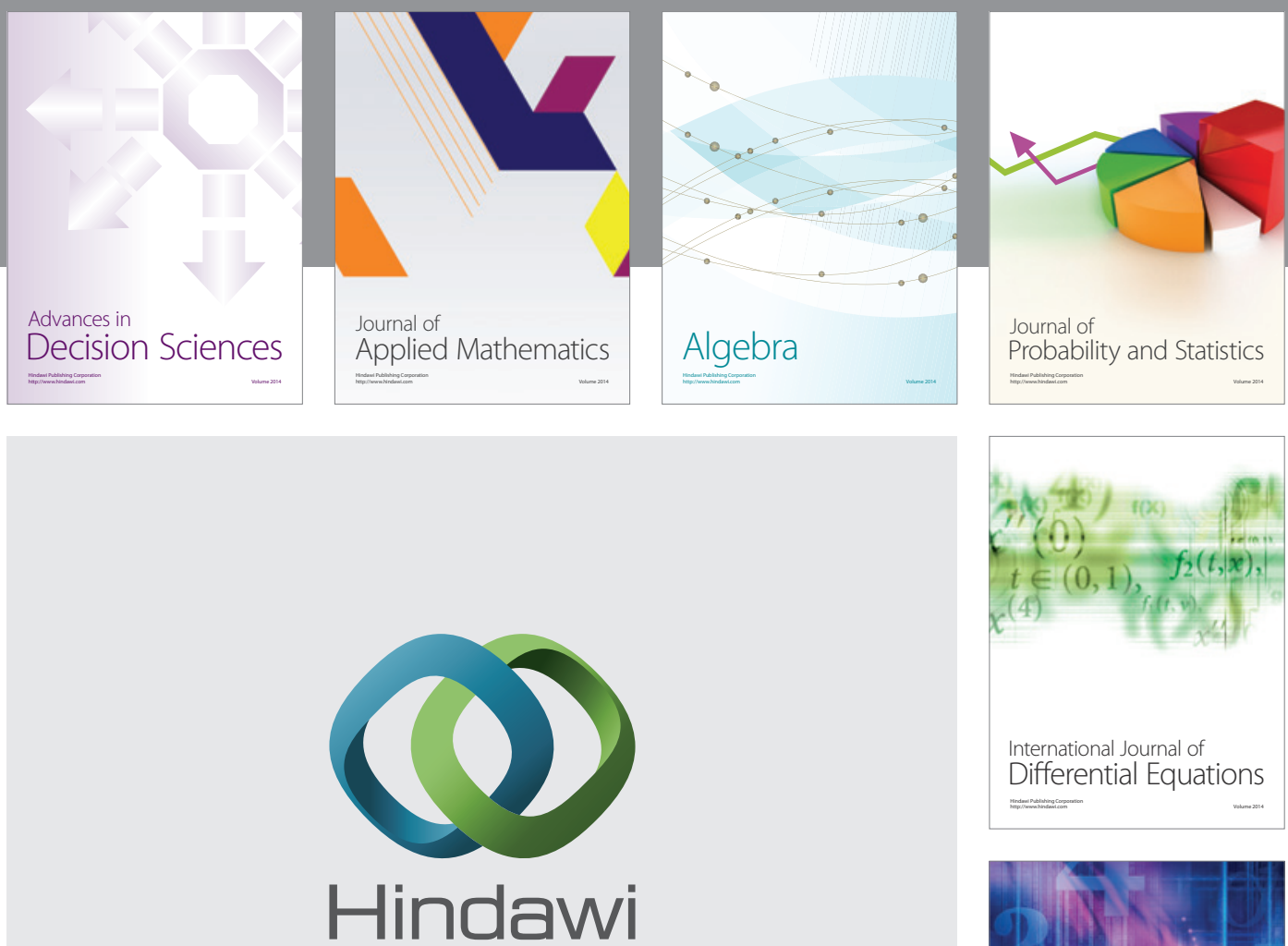

Submit your manuscripts at http://www.hindawi.com
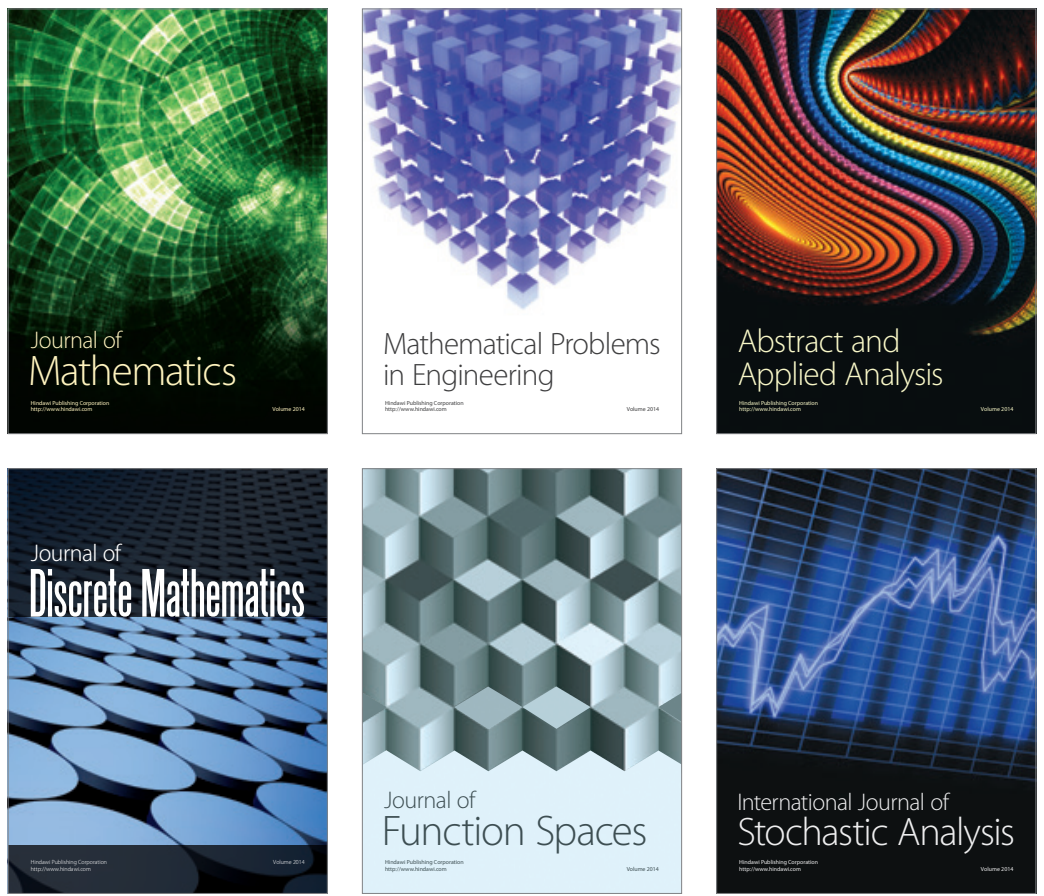

Journal of

Function Spaces

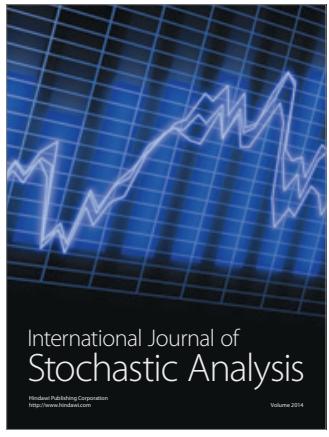

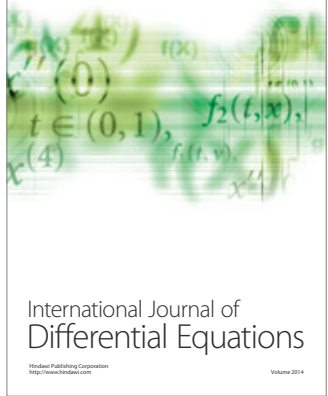
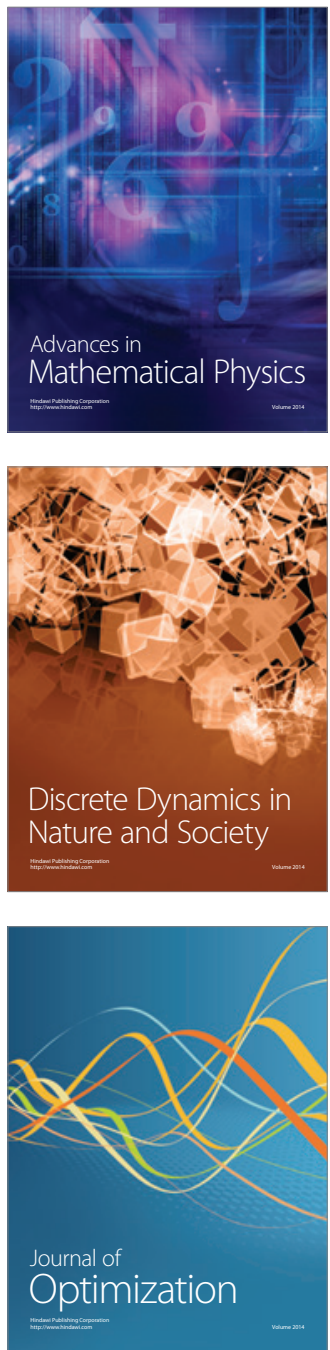